\title{
Impact of Epidemiological Publications among Health Professionals in Disease Surveillance - Experience from Jaffna, Sri Lanka
}

\author{
Chandrasekar $\mathrm{K}^{1}$, Mahesan $\mathrm{S}^{2}$ and Bath $\mathrm{PA}^{3}$ \\ ${ }^{1}$ Library, University of Jaffna, Sri Lanka \\ ${ }^{2}$ Department of Computer Science, University of Jaffna, Sri Lanka \\ ${ }^{3}$ Information School, University of Sheffield, UK
}

\begin{abstract}
Epidemiological publications are generally published at national level as a source of feedback for surveillance data provided by the preventive health sector at regional and local levels. In this connection, WER and QEB published by the Epidemiology unit are considered as the chief source of current epidemiological information in Sri Lanka. This study explores the significance of these epidemiological publications, examines the awareness and utilisation of these publications among health staff, analyses the perception of health staff regarding the quality of information carried in these publications and assesses the influence of these publications on policy decisions. This study was carried out among health staff engaged in notifiable disease surveillance activities in Jaffna District, Sri Lanka. A qualitative approach, using in-depth semi-structured interviews was used. Even though WER and QEB are published to serve the purpose of disseminating epidemiological information related to Sri Lanka, their outreach is not satisfactory. In Jaffna, the factors such as limited circulation, lack of awareness, problems in accessibility, time delay in publication and language barrier are contributing to the poor utilisation of these publications among health professionals and health workers. Efforts should be taken at national level to ensure the accessibility and to improve the utilisation of these epidemiological publications. Initiatives at regional level to collect, collate and publish epidemiological information is also essential.
\end{abstract}

KEYWORDS: Epidemiological publications, Health information access, Sri- Lanka, Health professionals, Communicable disease surveillance

Corresponding author: K. Chandrasekar, Email: kchandrasekar@univ.jfn.ac.Ik 


\section{INTRODUCTION}

Information has become an essential commodity nowadays and up-to-date information is vital for decision making, action and research in any discipline. Demand for good-quality health information is growing in order to provide quality healthcare (Lippeveld et al., 2000). The upsurge of demand for health information could be adequately met with, through the development of effective health information systems (HIS). HIS is a process through which health-related data are gathered, shared, analysed and used for decision-making (Lippeveld et al., 2000; Smith, 2000). In a way, it could be explained as the transformation of information into knowledge for action.

\section{BACKGROUND}

In recent years, much interest has been shown by the health service managers and public health specialists in restructuring the information systems of the primary healthcare, as a way of improving health care delivery (Hutchison et al., 2011; WHO, 2008). This is because, it provides majority of healthcare services and function as a first point of contact for $75-85 \%$ of the population in the need of healthcare. Public health surveillance systems are considered as one of the important components of these primary healthcare systems, which support public health activities by providing timely, quality information (Rajeev et al., 2010; WHO, 2000).

A typical public health surveillance system constitutes with infectious (communicable) diseases, accidents and injuries, chronic conditions, environmental and occupational hazards, maternal and child health, healthcare for elderly, behavioural risk factors, and health promotion as some of its essential components (Smith, 2000; Thacker and Stroup, 1994). Among these, surveillance systems for infectious diseases are critical in protecting the people from diseases, by providing necessary surveillance data for timely action (Jelastopulu et al., 2010; Kebede et al., 2011; Perry et al., 2007). Besides, newly emerging and reemerging infectious diseases and its consequences also reveal the significance of such systems (Calain, 2007; Hanafusa et al., 2012; Tambo et al., 2014).

Surveillance data generated through these systems are used for making policy decisions, identifying priority issues, planning and implementing surveillance programmes and allocating funds and resource in relation to communicable disease prevention and control (Calain, 2007). Further, in the present context it is much used in prediction and early detection of outbreaks (Hanafusa et al., 2012; Tambo et al., 2014). Several evaluation studies on existing communicable disease surveillance systems have been reported (Green and Kaufman, 2002; Jajosky and Groseclose, 2004; Janati et al., 2015; Thacker et al., 1983). However, studies related to the epidemiological publications and their usage among health workers is scarce.

In Sri Lanka, the Epidemiology unit (at national level) publishes Weekly Epidemiological Reports (WER) and Quarterly Epidemiological Bulletins (QEB) based on the surveillance data at regular intervals, in view of providing surveillance information of infectious diseases for timely action (Epidemiology Unit, 2016). Apart from WER and QEB, the Annual Health Bulletin (AHB) published by the Department of Health services also carries epidemiological information. Since 2005 the Statistical handbook for the Jaffna District is published annually by the Regional Directorate of Health Services office (Jaffna) at the regional level (RDHS, 2015). It includes epidemiological statistics of notifiable disease incidences in Jaffna District. In addition, Suhamanchari, a quarterly magazine on health (in Tamil language) is currently published by the Association for Health Education and Development (AHEAD) (previously published by the Department of Community medicine, Faculty of Medicine, University of Jaffna), to 
create health awareness among the general public and update health workers with necessary information related to health issues pertaining to the northern region of Sri Lanka.

In this study, the WER and QEB of the Epidemiology unit are considered primarily as they are the official publications of the government at the national level and provide epidemiological statistics and surveillance information with regard to whole country. This paper intends to assess the role of these publications as a source of disseminating epidemiological information and impact of these publications among health staff, those who are engaged in disease surveillance activities in Jaffna, Sri Lanka.

\section{METHODOLOGY}

A qualitative study (using in-depth semistructured interviews) was carried out among health staff engaged in notifiable disease surveillance activities in Jaffna District (Sri Lanka) by adopting the methodology recommended by Corbetta (2003) and Pope and Mays (1995). Ethical clearance for this study was obtained from the Ethical Review Committee, Faculty of Medicine, University of
Jaffna, Sri Lanka. The main inclusion criterion for participants was them being engaged in work related to the notifiable disease surveillance system at a local level (Jaffna, Sri Lanka). In addition, officers related to disease surveillance program at regional and national levels (in Sri Lanka) were also recruited. Participants of all categories were selected randomly, from the list prepared for the selected location (Jaffna District) (Table 1). Letter of invitation along with information sheet and reply slip were sent to the selected participants, inviting them to participate in the study and also recruited via snowball sampling as found necessary. Interviews with all the respondents were tape recorded with their consent.

A pilot study was carried out with the first five interviews, and the suitability of the interview guide was assessed and slightly modified after the pilot study. In order to maintain a flow in the interview, the order of the questions were changed. All 38 participants were interviewed and recorded (Table 1). All the interviews were transcribed and analysed. Thematic analysis approach was used to identify emerging themes from the data, as suggested by Marshall and Rossman (1999) and Mason (2002). At the end, audit trial was conducted to check the validity of the study.

Table 1: Recruitment summary of participants at Jaffna

\begin{tabular}{|l|l|c|}
\hline Healthcare Professionals (Categories) & Responsibilities & $\begin{array}{c}\text { No. of } \\
\text { Participants }\end{array}$ \\
\hline Consultant Epidemiologists (Colombo) & $\begin{array}{l}\text { Analysis of Infectious disease (ID) surveillance } \\
\text { data, dissemination of findings, and take appropriate } \\
\text { action at national level }\end{array}$ & 2 \\
\hline $\begin{array}{l}\text { Regional Director of Health Services } \\
\text { (RDHS) }\end{array}$ & $\begin{array}{l}\text { Chief administrator of the health system at regional } \\
\text { level }\end{array}$ & 1 \\
\hline Regional Epidemiologist (RE) & $\begin{array}{l}\text { Monitor the reporting (at the regional level) of } \\
\text { detected ID cases to the public health system at } \\
\text { national level }\end{array}$ & 1 \\
\hline Director/ Jaffna Teaching Hospital (JTH) & $\begin{array}{l}\text { Monitor the reporting (at the institutional level) of } \\
\text { detected ID cases to the public health system at } \\
\text { local level }\end{array}$ & 1 \\
\hline
\end{tabular}


Kalpana Chandrasekar et al.

\begin{tabular}{|l|l|c|}
\hline Medical Officers of Health (MOHs) & $\begin{array}{l}\text { Report the confirmed ID cases to the public health } \\
\text { system at national level }\end{array}$ & 3 \\
\hline $\begin{array}{l}\text { Supervising Public Health Inspectors } \\
\text { (SPHIs) \& Public Health Inspectors } \\
\text { (PHIs) }\end{array}$ & $\begin{array}{l}\text { Investigation of infectious disease cases by the } \\
\text { public health system at local level }\end{array}$ & 7 \\
\hline $\begin{array}{l}\text { Infection Control Nursing Officer (ICNO) } \\
\text { / Medical Record Assistant (MRA) }\end{array}$ & $\begin{array}{l}\text { Recording and reporting of infectious disease cases } \\
\text { to the public health system at local level }\end{array}$ & 2 \\
\hline General Practitioners (West. Med., Govt.) & $\begin{array}{l}\text { Detection, registration, reporting and treatment of } \\
\text { infectious disease cases }\end{array}$ & 10 \\
\hline General Practitioners (West. Med., Pvt.) & $\begin{array}{l}\text { Detection, registration, reporting and treatment of } \\
\text { infectious disease cases }\end{array}$ & 3 \\
\hline Traditional Physicians (Indi. Med., Govt.) & $\begin{array}{l}\text { Detection, registration, reporting and treatment of } \\
\text { infectious disease cases }\end{array}$ & 2 \\
\hline Traditional Physicians (Indi. Med., Pvt.) & $\begin{array}{l}\text { Detection, registration, reporting and treatment of } \\
\text { infectious disease cases }\end{array}$ & 3 \\
\hline Medical Laboratory Technicians (MLTs) & Confirmation of the infectious disease & 2 \\
\hline WHO Consultant/Coordinator & Representative of the WHO & $\mathbf{3 8}$ \\
\hline Total No. of Participants & & 2 \\
\hline
\end{tabular}

\section{RESULTS AND DISCUSSION}

As in any other field, information has become an essential commodity in health services too. Regarding disease surveillance, epidemiological publications are the main sources of current epidemiological information. However, scarcely any literature was found on the usage of epidemiological publication. Hence, this study examined the impact of epidemiological publications among health professionals and health workers in a selected geographical location (Jaffna District) in Sri Lanka.

Sri Lanka is a developing country in Asia with a land area of approximately 62,705 square kilometers and a population of approximately 20 million. In addition to allopathic system of medicine, the Siddha, Ayurveda, Unani, Acupuncture and Homeopathy systems are also practised in Sri Lanka. Jaffna District is located in the Northern Province of Sri Lanka, which was severely affected by 30 years of civil war in Sri Lanka. Moreover, Health services in the Jaffna District (Sri Lanka) are delivered to a population of approximately 610,640 (as at December 31, 2013) (Department of Census and Statistics, 2016), through 11 Medical Officers of Health $(\mathrm{MOH})$ units, 105 allopathic, and 116 indigenous medical institutions located (both in the government and private sectors) (Table 2).

Table 2. Distribution of Healthcare institutions in Jaffna, Sri Lanka

\begin{tabular}{|l|l|c|}
\hline \multicolumn{2}{|c|}{$\begin{array}{c}\text { Healthcare Institutions at Jaffna } \\
\text { (Categories) }\end{array}$} & $\begin{array}{c}\text { Total } \\
\text { Number }\end{array}$ \\
\hline $\begin{array}{l}\text { Western medical } \\
\text { institutions }\end{array}$ & $\begin{array}{l}\text { Government } \\
\text { sector }\end{array}$ & 43 \\
\cline { 2 - 3 } & Private sector & 62 \\
\hline \multirow{2}{*}{$\begin{array}{l}\text { Indigenous medical } \\
\text { institutions }\end{array}$} & $\begin{array}{l}\text { Government } \\
\text { sector }\end{array}$ & 42 \\
\cline { 2 - 3 } & Private sector & 74 \\
\hline Medical laboratories & & 09 \\
\hline MOH Offices \& RDHS Office & 12 \\
\hline \multicolumn{2}{|c|}{ Total } & $\mathbf{2 4 2}$ \\
\hline
\end{tabular}


In this study, it was observed that the majority of the health staff do not have adequate facilities at their workplaces for updating their medical knowledge. In Jaffna, JTH and BH Point Pedro have library facilities other than the library at the Faculty of Medicine at the University of Jaffna. No other hospitals have such facilities. Further, western medical practitioners in the private sector and traditional medical practitioners depend largely on the media for current information. Apart from these sources, some medical practitioners on their own interest subscribe to foreign medical journals and newsletter of Jaffna Medical Association.

Regarding disease surveillance, epidemiological publications published by the Epidemiology unit (at national level) are considered as a source of feedback for surveillance data provided at regional and local levels, in Sri Lanka. This study analysed and revealed the issues related to these official publications (WER and QEB) of the Epidemiology unit, in connection with communicable disease surveillance. Significance of these epidemiological publications, awareness and utilisation of these publications among health staff, the quality of published information and the influence of these publications on policy decisions are discussed in detail, in the following section.

\subsection{Significance and awareness of epidemiological publications among health staff}

The significance of these epidemiological publications is twofold. These publications serve as a feedback to surveillance data collected through the surveillance process, and feature article (on health issues of current interest) in each issue of the WER is informative as well as helpful in disease prevention and control activities. In the WER, the surveillance data are usually presented and documented in the form of statistical tables. This would enable the health staff to identify the disease pattern in a specific locality, to compare the prevalence of a particular disease in different regions, and to take early action in case of disease outbreaks. It was pointed out in the interview that these epidemiological statistics are very essential for providing factual justification to obtain financial assistance for prevention and control programmes of infectious diseases.

Regarding the awareness of these epidemiological publications among health staff attached to western medical system, it was observed that majority of the health officers are aware of these publications, because they have been taught about these epidemiological publications during the medical training; and some have used them for their research as well. Moreover, in the preventive sector, public health workers are made aware of these publications during their in-service training programmes and advised to read those publications in order to update their knowledge. However, accessibility and language are the major barriers that affect their interest towards these publications, which is discussed under the section 'utilisation of epidemiological publications'.

With regard to indigenous medical system, preventive healthcare is not a separate component. As such, most of the traditional medical practitioners are not aware of these publications. On the other hand, institutionally trained indigenous medical practitioners are however aware of these publications. Furthermore, lack of epidemiological publications in the indigenous medical system is also found to be a major drawback.

\subsection{Utilisation of epidemiological publications}

In relation to utilisation, it was observed that usage of these epidemiological publications by health workers in Jaffna is very poor. This is mainly due to problems in accessibility, timeliness of publication and medium of publication. One of the Consultant epidemiologists at the Epidemiology unit reported that they are sending their epidemiological publications (WER and QEB) 
to all the healthcare institutions in the government sector free of charge. At the same time, these publications are also publicly accessible in their Epidemiology unit website. However, no assessment has been made so far on the extent of utilisation of these publications at a local level.

In Jaffna, access to these publications is limited. It is available only in 34 medical institutions (out of 242) such as RDHS office, $\mathrm{MOH}$ offices, hospitals with inpatient facilities, JTH and Faculty of Medicine, University of Jaffna. None of the traditional medical institutions, western medical institutions in the private sector and primary healthcare units in the government sector are supplied with these publications (Table 2), nor the public health inspectors who are the field level staff involved in prevention and control of infectious diseases.

One western medical practitioner of the study stated that the Epidemiology unit sends one copy of their publications to each $\mathrm{MOH}$ and expects the $\mathrm{MOH}$ to distribute copies to all PHI areas under their purview. This is not practically feasible at $\mathrm{MOH}$ level due to financial constraints. Suggestion for an alternative way given by a participant is:

They [Epidemiology unit] must send a bundle to the RDHS. There are only 25 districts. So, the Epidemiology unit will have to send only 25 bundles... to the 25 RDHS. And each RDHS divided into 25-30 PHIs. So, the work is... if you ask the Epidemiology unit to send 25 X 25... 625 forms to everybody that is... that's why it doesn't work. (WHO Consultant)

As he suggested, the work has to be decentralised in order to disseminate the information.

Apart from public health workers, even in hospitals copies of the epidemiological publications are kept in the library or administrative office of the institution without being circulated among the medical officers attached to those hospitals. Further, it was suggested by the participants that as these publications also function as a feedback for the notifications sent by the medical practitioners, its accessibility for concerned people has to be ensured. She stated:

if it is beautifully filed and kept, then what is the use? You know, where these mistakes... because of which, the doctors are not actively involved. Because, they are not made aware of what is happening or what has been done. (Western medical practitioner/Hospital)

It was also pointed out that unless feedback is given to those who notified, they will not bother continuing notification:

.... If you train these people and get them to contribute to the notification, then it is obligatory on the part of the Epidemiology unit to send them the... what they sent. Because, unless you have a two-way communication... now say, if I send notifications regularly and I don't get any feedback... I am not going to stick on to that. (WHO Consultant)

It was also observed that these epidemiological publications do not reach the primary healthcare units in the government sector nor the medical institutions in the private sector. When inquired regarding this at the preventive sector, the reply was:

these Private practitioners... if they are interested to know about the present status... we can from the local MOH.... we can give the particulars. (Health administrator/Regional level)

However, medical practitioners in the private sector are not ready to contact any source for surveillance information, because they are more concerned with diagnosis and treatment of diseases and expect that the surveillance information should be disseminated to them by the preventive sector. Though, these medical practitioners do not send notifications to the 
$\mathrm{MOH}$ or Epidemiology unit when they come across cases with notifiable diseases. Further, such epidemiological publications do not exist in the traditional medical system. Hence, it is important to improve the accessibility of the epidemiological publications of the Epidemiology unit to public health workers and western medical practitioners in the private sector as well as in the government medical institutions with inpatient care. In addition, traditional medical practitioners and government medical institutions with outpatient care should also be provided with access to these publications. One suggestion given by a respondent is that more responsibilities have to be given to the regional level in relation to coordination of surveillance activities.

if the Epidemiology unit communicates with the... what I say was now say, if all the notifications go to the RE. The RE must send the weekly returns to the people who... send the notifications. It's only then, they get encouraged and they'll continue to send. Instead of... you see, if you allow them to send it to the respective MOH... eh... we don't know... nobody knows whether they are sending or not. But, if you can get it... the RE get it, but of course it'll be a little work for you... extra work. Then, he can sort out... right... this is... this man... this man... and send it. And then, even the WER... if it comes... can access it and get printouts or something and post it to the... Because, I don't know whether all the Private practitioners will have access to the websites. But, they can... at least, hardcopies can be sent to the... So that, you develop a rapport. (WHO Consultant)

Regarding the issue of public access to these epidemiological publications, it was pointed out that these publications are very technical and cannot be understood by the public. However, the content of these publications is very useful even for the public. So it was recommended that it should be the duty of the Health Education Officers (HEOs) in the preventive sector to interpret it and disseminate the information to the public, via health education programmes.
Another important problem related to utilisation of epidemiological publications is the timeliness of these publications. Since the notifiable disease status at different districts in Sri Lanka is presented in WER, it would serve the purpose of taking early measures to prevent the spreading of diseases (especially from one district to another) only if it reaches the hands of public health workers on time. One of the major issues pointed out by several participants is the time taken for these publications.

1-1 1/2 months delay in WER; three months delay in QEB; Then, approximately one year delay when it comes to $A H B$...... (SPHI)

Due to this delay in publication, most of the time, information in these publications gets outdated when it reaches the hands of public health workers. When queried regarding this long delay in publication, one of the Consultant epidemiologists at the Epidemiology unit stated that they had not been getting any allocation from the government for these publications and it depends exclusively on the support from UNICEF; they also bear the printing cost of the English version of WER. The cost for posting these publications is somehow managed by the Epidemiology unit, which is also expensive.

Comparatively, publishing it on the Epidemiology website would be less expensive, but, it will not reach the required audience unless satisfactory IT facilities are provided at a local level. Further, it was observed that financial constraints are the main issue for the limited distribution of these publications. It was also reported at the Epidemiology unit level that if any private practitioners request an individual copy of these epidemiological publications they will send it. However, due to inadequate funding facilities it is not feasible for the Epidemiology unit to distribute these publications to private practitioners throughout the country. Apart from these, postal delays also affected the timely delivery of these publications. It was a serious problem in Jaffna during the unrest period, sometimes they got lost in the post too. 
Language also hinders the utilisation of these publications at public health inspectors' level. Usually public health workers are trained in the local languages, namely Sinhala and Tamil. Hence, they are not able to understand these publications in English. As such, it is advised by the Epidemiology unit to summarise the content of these publications in the epidemiological meetings conducted at $\mathrm{MOH}$ level. However, the problem in Jaffna is that all MOH areas (except for one) are functioning with the help of SPHI or PHI as an Officer in-charge in-lieu of an $\mathrm{MOH}$. In this situation, it is not feasible in Jaffna to carry out such activities. However, the Epidemiology unit had taken steps to publish WER in local languages, but, due to inadequate financial assistance and lack of translation facilities, they find it difficult to continue after publishing a few issues. The same difficulties were pointed out at regional level in Jaffna also, in addition to human resource shortage, when enquired whether they would be able to do it at regional level.

\subsection{Quality of information in epidemiological publications}

The information provided in these publications is highly technical and helpful in preventive activities in addition to updating the knowledge of health personnel. Among several health related publications by the Ministry of Health, WER and QEB are the important publications related to disease surveillance published by the Epidemiology unit at national level. WER contains data from notification and feature articles on issues or topics which are of current interest to health staff, published weekly. Usually these feature articles provide information on the latest situation of the disease, diagnosis, prevention and management, in order to update the health staff. Besides, QEB is published on a quarterly basis and includes a detailed discussion on the notifiable diseases situation in the country for a particular quarter. Almost all the participants in this study expressed their satisfaction with these publications.
Regarding the quality of information in these publications, it was observed that most participants are impressed by the feature articles in WER. However, completeness and timeliness of notification statistics presented in the WER are not up to the desired quality. Further, during the past several years, notification statistics of Jaffna district did not reach the Epidemiology unit in time due to postal delays and transport difficulties. Therefore, in WER it was indicated as 'not applicable' against Jaffna district. This was a big disappointment to the preventive health staff in Jaffna district, those who had worked under several difficulties and maintained the surveillance statistics. Currently, the situation is improving and surveillance data are sent to the Epidemiology unit by e-mail from RDHS office, in order to maintain the timeliness. Besides this, notification statistics help the preventive sector in identifying the prevalence of notifiable diseases in their area and compare the disease occurrence in their district with that in other districts. However, it is commented by one of the preventive sector staff that notification data without an analytical discussion (in WER) is difficult to understand. Further, he also pointed out that rather than notified cases, it would be more helpful if statistics of confirmed cases are presented, being separated from suspected cases which are normally included in the notified cases.

Besides, specialised campaigns exist for certain notifiable diseases in addition to the routine surveillance system of Sri- Lanka. These campaigns were formed in order to collect additional information on priority health issues, as the data delivered by the routine surveillance system were insufficient. It was observed that the surveillance statistics reported by the routine surveillance system differs from that reported by these specialised campaigns. This is due to lack of coordination between these two systems at local and regional levels. To overcome this problem it was suggested by a western medical practitioner that authority for disseminating the information related to these particular notifiable diseases should be given to one system and it is 
accepted that data from specialised campaigns are more reliable.

\subsection{Influence of epidemiological information on policy decisions}

Generally, surveillance statistics presented in these epidemiological publications have an impact on policy decisions taken at a national level, by providing justification with statistical evidence. Even though policy decisions are made at national level, the implementation part has to be carried out by the Provincial councils, due to devolution of powers according to the 13th amendment to the Sri Lankan constitution. Due to poor coordination at national and provincial levels, it was observed that the implementation part of health policies is not carried out satisfactorily.

Further, in relation to health policies, these surveillance statistics provide clear justifications on certain issues such as whether to introduce a new vaccine, measures to be taken when an infectious disease is spreading in an epidemic proportion, etc. Moreover, foreign aid for certain health projects is obtained and external assessments are also carried out based on these statistics. It was also pointed out by a public health worker that the newly revised forms for notification and investigation revealed that the suggestions given by them at local and regional level meetings are considered in designing these forms. Actually the revised forms reduce the duplication of work and requests for certain additional information.

Usually in the health sector, policy decisions are made at the top and are transferred down to the bottom level, where no policy decisions are made at all. A western medical practitioner expressed his views as:

DGHS coming, asking us... talking to us. Epidemiologist coming... presenting his report. Informing that... Dengue in Puttalam is so much... Kurunagal is so much. Who is studying this report... who is responsibly acting on these.
Information that they are getting... then policy decision... feedback. Whether these things are happening... nobody look into that.

(Western medical practitioner/Hospital)

According to the views of the participants, higher authorities are burdened with added responsibilities and thus lack time for fulfilling each and every matter in health and some authorities behave irresponsibly but escaping from disciplinary actions as well.

\section{CONCLUSION}

Even though these epidemiological publications are introduced to serve the purpose of disseminating the epidemiological information related to Sri Lanka, their outreach is not satisfactory. Due to financial constraints, these publications are published in limited numbers and distributed to government hospitals with inpatient facilities, RDHS, RE, MOH officers and medical educational institutions, but not to any other institutions or officers. As such, only $14 \%$ of the medical institutions in Jaffna are getting these publications. Indigenous medical institutions, western medical institutions in the private sector, government medical institutions with outpatient care and PHIs are not supplied with these publications and results in lack of awareness. They should be supplied with these publications because nearly $50 \%$ of the outpatients in Jaffna are treated in the private sector, and PHIs are the field level staff, who are involved in disease surveillance activities. It is essential that indigenous medical practitioners should also be made aware of these epidemiological publications.

Apart from awareness, factors such as problems in accessibility, timeliness of publication and medium of the publication are also affecting the effective utilisation of these publications. Regarding the quality of information provided in these publications, most of the participants are satisfied, except for a few, who expect the matters a bit more understandable. The extent of 
utilisation of surveillance statistics in policy decision making at local level is limited due to lack of interest and it is considered as a responsibility of higher authorities.

This study revealed that adequate efforts should be taken at national level to ensure the accessibility and to improve the utilisation of these epidemiological publications among health professionals and health workers at a local level. Initiatives should be taken to publish epidemiological information at regional level. Further, dissemination of health information to the community through health education programmes should be the responsibility of the regional and local level health authorities. It is also recommended to have a website for every RDHS division in order to furnish health sector issues (including disease surveillance particulars), along with IT facilities at peripheral healthcare institutions to have access to the website.

This paper examined the influence of official publications (WER and QEB) of the Epidemiology unit (Sri Lanka) on disease surveillance, and proposed suggestions to improve effective utilization of these publications among health professionals and health workers. Moreover, this study would enlighten the health workers on the importance of epidemiological information related publications and their wider access, in view of prevention and control of infectious diseases. Above all, this study intended to make a contribution to the health information access, as existing literature related to epidemiological publications is limited.

\section{ACKNOWLEDGEMENT}

We thank all the participants of this study for their support. Financial assistance was obtained under a Commonwealth Split-site Doctoral Scholarship tenable in the UK.

\section{REFERENCES}

CALAIN PHILIPPE. Exploring the international arena of global public health surveillance. Health Policy and Planning 2007; 22: 2-12.

CORBETTA P. Social research: theory, methods and techniques. London: Sage Publications. 2003.

DEPARTMENT OF CENSUS AND STATISTICS, Sri Lanka. Available in http://www.statistics.gov.lk/DistrictStatHBook. asp?District=Jaffna. Accessed on June 2016.

EPIDEMIOLOGY UNIT, Sri Lanka. Available in http://www.epid.gov.lk. Accessed on May 2016.

GREEN MS \& KAUFMAN Z. Surveillance for early detection and monitoring of infectious disease outbreaks associated with bioterrorism. Israel Medical Association Journal. 2002; 4(7): 503-6.

HANAFUSA S, MUHADIR A, SANTOSO H, TANAKA K, ANWAR M, SULISTYO E \& HACHIYA M. A surveillance model for Human Avian Influenza with a comprehensive surveillance system for local-priority communicable diseases in South Sulawesi, Indonesia. Trop Med Health. 2012; 40(4): 1417.

HUTCHISON B, LEVESQUE JF, STRUMPF E \& COYLE N. Primary health care in Canada: systems in motion. Milbank Quarterly. 2011; 89: 256-88.

JAJOSKY RA \& GROSECLOSE SL. Evaluation of reporting timeliness of public health surveillance systems for infectious diseases. BMC Public Health 2004; 4(29). Available in http://www.biomedcentral.com/14712458/4/29. Accessed on March 2007. 
JANATI A, HOSSEINY M, GOUYA MM, MORADI G \& GHADERI E. Communicable disease reporting systems in the World: a systematic review article. Iranian Journal of Public Health. 2015; 44(11): 1453-65.

JELASTOPULU E, MEREKOULIAS G \& ALEXOPOULOS EC. Underreporting of communicable diseases in the prefecture of Achaia, western Greece, 1999-2004 - missed opportunities for early intervention. Euro Surveillance. 2010; 15(21): 1-6.

KEBEDE S, GATABAZI JB, RUGIMBANYA P, MUKANKWIRO T, PERRY HN, ALEMU W, NDIHOKUBWAYO JB, KRAMER MH \& MUKABAYIRE. Strengthening systems for communicable disease surveillance: creating a laboratory network in Rwanda. Health Res Policy System. 2011; 9: 1-8.

LIPPEVELD T, SAUERBORN R \& BODART C. (eds.). Design and implementation of health information systems. Geneva: World Health Organization. 2000.

MARSHALL C \& ROSSMAN GB. Designing qualitative research. London: Sage Publications. 1999.

MASON J. Qualitative researching. 2nd edition. London: Sage Publications. 2002.

PERRY HN, McDONNELL SM, ALEMU W, NSUBUGA P, CHUNGONG S, OTTEN MW, LUSAMBA-DIKASSA PS \& THACKER SB. Planning an integrated disease surveillance and response system: a matrix of skills and activities. BMC Med. 2007; 5(1): 24.

POPE C \& MAYS N. Qualitative research: reaching the parts other methods cannot reach: an introduction to qualitative methods in health and health services research. British Medical Journal. 1995; 311: 42-5.

RAJEEV D, STAES CJ, EVANS R, MOTTICE $\mathrm{S}$, ROLFS R, SAMORE MH, WHITNEY J,
KURZBAN R \& HUFF SM. Development of an electronic public health case report using HL7 v2.5 to meet public health needs. J Am Med Inform Assoc. 2010; 17(1): 34- 41.

REGIONAL DIRECTOR OF HEALTH SERVICES. Statistical Handbook - 2014. Jaffna: RDHS Division. 2015.

SMITH J. Health management information systems: a handbook for decision makers. Buckingham: Open University Press. 2000.

TAMBO E, UGWU EC \& NGOGANG JY. Need of surveillance response systems to combat Ebola outbreaks and other emerging infectious diseases in African countries. Infect Dis Poverty. 2014; 3(1): 1-8.

THACKER SB \& STROUP DF. Future directions for comprehensive public health surveillance and health information systems in the United States. American Journal of Epidemiology. 1994; 140(9): 383-97.

THACKER SB, CHOI K \& BRACHMAN PS. The surveillance of infectious diseases. The Journal of the American Medical Association. 1983; 249(9): 1181-5.

WORLD HEALTH ORGANIZATION. An integrated approach to communicable disease surveillance. Weekly Epidemiological Record. 2000; 75(1): 1-7.

WORLD HEALTH ORGANIZATION. The World health report 2008: primary health care now more than ever. Geneva: World Health Organization. 2008. 